\title{
Therapeutic interventions for trunk and improvement of posture in children with cerebral palsy: a review of the literature
}

\begin{abstract}
Background: Cerebral Palsy (CP) is associated with disorders of movement, posture and intellectual activities which are due to a non-progressive lesion or damage to the immature brain and can be range from mild to profound.

Objective: The aim of this literature review is to investigate and analyze the effectiveness of four new - in the last twenty years - modern therapeutic interventions (Hippotherapy, Virtual Reality, Aquatic Therapy and Adeli Suit Therapy) in the trunk and improvement of posture in children with cerebral palsy.
\end{abstract}

Methods: After searching databases like Pubmed, Science Direct, Medline, Pedro, QMU e-Library and Cochrane Library for the period of 1995 to 2015, the total of 250 papers were retrieved. The studies consisted of children of all ages, diagnosed with CP. Only 73 of the studies were meeting the inclusion criteria.

Results: Forty-four trials were indentified. Four intervention categories were distinguished (virtual reality therapy, hippotherapy, aquatic therapy and Adeli or Thera suit therapy). The results showed that each of the four therapies analyzed can be effective in improving trunk control and posture with or without additional physical therapy. However, further research is needed due to the diversity among types and severity of CP.

Conclusion: Aquatic Therapy, Hippotherapy, Virtual Reality and Adeli/Thera Suit showed efficiency in treatment programs of children with CP. Future research studies must accommodate the effectiveness of these techniques and should improve the ability to target them at community and family levels.

Keywords: cerebral palsy, adeli suit treatment, thera suit, hippotherapy, virtual reality, aquatic therapy, hydrotherapy
Volume 10 Issue 4 - 2018

\author{
D Fragkou, ${ }^{\prime}$ G Gkrimas, ${ }^{2}$ M Pyrgeli ${ }^{3}$ \\ 'Physiotherapist \\ ${ }^{2}$ Biomechanist, Head of Gait \& Motion Analysis Center, ELEPAP \\ Athens \\ ${ }^{3}$ Doctor of Physical \& Rehabilitation Medicine, Scientific \\ Director of ELEPAP Athens
}

\section{Correspondence: M Pyrgeli, Doctor of Physical \& \\ Rehabilitation Medicine, Scientific Director of ELEPAP Athens, \\ Greece,Email mariapyrdoc@yahoo.gr}

Received: July 12, 2018 | Published: July 31, 2018
Abbreviations: CP, cerebral palsy; VR, virtual reality; QoL, quality of life; TCMS, trunk control measurement scale; GMFM 66,88, gross motor function measures; PBS, pediatric balance scale; NDT, neurodevelopmental treatment; EIHB, mechanical efficiency index; PEDI, pediatric evaluation of disability inventory; PEDI-FSS, pediatric evaluation of disability invento functional status score; WOTA2, water orientation test alyn 2; MAS, modified ashworth scale; COPM, canadian occupational performance measure; M-ABC, movement assessments battery for children; PSPCSA, pictorial scale of perceived competence and social acceptance; EMG, electromyography; SEMG, surface EMG; AIM, aquatic independence measure; GMFCS, gross motor function classification system; PCC, Perceived physical and social competence; SAS, sitting assessment scale; BPM, balance performance monitor; DLS, double-leg stance; OLS, one-leg stance; vGRF, vertical ground reaction force; RFD, rate of force development; VMC, video motion capture; AMS, abductor muscle symmetry; BOMTP, Bruininks-oseretsky test of motor proficiency; hVCT, home-based virtual cycling training

\section{Introduction}

Cerebral Palsy (CP) is defined as static encephalopathy due to brain injury before the full development of the cerebrum. ${ }^{1}$ Owing to the development of the brain in the first two years of life, $\mathrm{CP}$ can occur at birth or in early childhood and insist throughout the individuals' life. ${ }^{2}$ About $70 \%-80 \%$ cases are referred in the prenatal period and with no obvious cause. ${ }^{1} \mathrm{CP}$ is a non progressive motor impairment influencing the physical and often intellectual activity of the patients. ${ }^{3}$ The two categories that $\mathrm{CP}$ is classified are by type of movement disorder and by anatomic distribution. In $\mathrm{CP}$ the most frequent movement pattern is spastic whereas dyskinetic, hypotonic, ataxic and mixed form movement patterns are more seldom. ${ }^{4}$

$\mathrm{CP}$ is the most frequent motor disability in childhood and as a result the prevalence of $\mathrm{CP}$ is estimated at about 3,6 per 1000 in children going to school. ${ }^{4}$ Severe $\mathrm{CP}$ can be associated with a reduced life expectancy. ${ }^{5}$ As the person with CP develops, the clinical picture changes and is characterized by brain lesions even when CP is not progressive. ${ }^{4}$ Thus, CP brings in numerous problems that affect the whole individual such as significant musculoskeletal and movement disorders. These are presented in Appendix 1.

More specifically for trunk and posture disorders, activities like reaching and walking activate the truck which should remain a stable base of support during execution of upper or lower limb movements. ${ }^{6}$ Therefore, poor trunk control has direct influence in daily activities 
like sitting and it is one of the primary problems in children with $\mathrm{CP}$. Postural control is related to stability and orientation, characteristics of the need the body has to maintain its position in space (Massion, 1998 cited in). ${ }^{8}$ Hence, posture control deficit is a restricting factor in children with CP. ${ }^{9}$ Additionally, the characteristic of spasticity can cause difficulties in postural control. ${ }^{10}$

\section{Appendix I}

\begin{tabular}{ll}
\hline Musculoskeletal \& Movement Disorders $^{2}$ \\
\hline Abnormal muscles tone $^{72}$ & Weakness $^{73}$ \\
Spasticity $^{72}$ & Impaired motor control $^{73}$ \\
Rigidity $^{72}$ & Poor $^{73}$ \\
Hypotonia $^{72}$ & Contracture $^{73}$ \\
Involuntary movements $^{72}$ & Skeletal Abnormalities (scoliosis) $^{73}$ \\
Dystonia $^{72}$ & Epilepsy $^{73}$ \\
Athetosis $^{72}$ & Poor trunk \& posture stability \\
\hline
\end{tabular}

As for the quality of life (QoL), children with CP seem to face lower QoL because of the limited participation in social or leisure activities and the restrictions in mobility. ${ }^{4}$ However, some findings show that children with CP have the potential to live and develop as all children of their age without any difficulty. ${ }^{11}$ Children and young people with mild CP have higher diversity and lower intensity of overall participation than those with severe CP. ${ }^{12}$ Physiotherapists as health professionals in the management of children with $\mathrm{CP}$ acquire a pivotal role which aims to restore the function, movement and optimal use of the child's potential and to give instructions to the child's parents on how to handle them at home. ${ }^{13}$ Therapy for children with CP has aims to meliorate the QoL for the family and the person with $\mathrm{CP} .{ }^{14}$ Some of the commonest therapeutic approaches being used in the rehabilitation of children with $\mathrm{CP}$, that show effectiveness in preceding studies are NDT, conductive education, strength training, orthotic devises $^{2}$ and PNF. ${ }^{14}$

Specifically, therapies which have gained recognition in the last years and seem to be more effective in trunk stability and posture are compared to more conventional therapies. For example, Aquatic Therapy and the aquatic programs consist of the Halliwick method, Ai Chi, Watsu, Feldenkrais and other programs depending on each case. ${ }^{15}$ Aquatic therapy or hydrotherapy often used as a term until 2008 is an aquatic program utilising the properties of water in order to improve function in a specially constructed and suitably heated hydrotherapy pool. ${ }^{16}$ One of the benefits of water is buoyancy which decreases the influence of gravity and increases postural support of children with $\mathrm{CP} .{ }^{17}$ Also, hippotherapy and the rationale behind hippotherapy is to mimic human gait patterns with the movement and gait of the horse. This has immediate effects on the rider's body because of the accurate, mild, rhythmic and repetitive movement. The effectiveness of hippotherapy is attributed to the mending of balance, posture, coordination, muscle strength and psychological effects. ${ }^{18}$

Virtual Reality (VR) rehabilitation which, is defined as "the use of interactive simulations created with computer hardware and software to present users with opportunities to engage in environments that appear to be and feel similar to real world objects and events". 19 Multimodal environments are a beneficial method of VR for rehabilitation treatment because of the advanced ongoing recalculation of the sensory inputs that would lead to suitable improvements of posture in a realistic context ambient. ${ }^{20}$ Bonnechere et al., ${ }^{21}$ also observed efficacy in posture in children with $\mathrm{CP}$.

Adeli or Thera suit Therapy is also used in CP patients. The Adeli suit is substantially a system of supporting elements composed of a special vest, shorts, knee caps, and footwear. Each pair of the supporting units is connected with a set of adjustable elastic ties called "Bungee".$^{19}$ This therapy has four stages. ${ }^{22}$ Some of the benefits of this approach are improvement of coordination by decreasing spasticity, balance improvement and readjusting the body in the right position. ${ }^{23}$ Since, there have been no other studies from the past decades that have discussed the efficiency of the four interventions on trunk and posture control in children with $\mathrm{CP}$, a literature review is required to summarize the effects of each intervention. Therefore, the purpose of this literature review is to analyze and assess the efficiency of the four interventions and find the most effective in trunk and posture control of children with $\mathrm{CP}$.

\section{Methods}

\section{Literature searches}

A search of the literature was carried out in order to acknowledge the appropriate articles. The databases that were searched consisted of: Pubmed, Science Direct, Medline, PEDro, the Cochrane library and the QMU e-Library from 1995 to 2015. The reference lists of the identified studies and reviews were examined for further references.

\section{Inclusion criteria}

The components examined for the inclusion of articles in this review are: 1. the type of study, studies published in peer reviewed journals, full-length articles (RCT's, clinical trials and case reports) since 1995,2 . The population, the participants have to be children or adolescents diagnosed with $\mathrm{CP}$ between the age of 3 and 18 years old. 3. The interventions that the studies use have to be clinically plausible physiotherapeutic interventions or a combination of these and 4 . The only language that is being used is English.

\section{Exclusion criteria}

Surgical and pharmaceutical interventions, acupuncture and hyperbaric oxygen therapy were excluded from this literature review. In addition, if the age limits and the condition did not comply with the criteria, the articles were excluded. Lastly, articles with different languages other than English were excluded.

\section{Assessment of methodological quality}

The Pedro scale was used in order to evaluate the methodological quality of half of the articles in this review. The methodological quality of RCT"s and quasi-RCT's are measured by this scale which is a tool developed for the measurement of this trials in physiotherapy. ${ }^{24}$ The Pedro scale includes 11 items: 1) inclusion criteria \& source, 2) random allocation, 3) concealed allocation, 4) baseline comparability, 5) blind subjects, 6) blind therapists, 7) blind assessors, 8) adequate follow-up, 9) intention to treat, 10) between groups comparison, 11) point estimates \& variability. This scale was scored for the total of 10 points as the first item is related to external validity. ${ }^{25}$ The use of Pedro scale is a valid tool for assessing methodological quality. ${ }^{26}$ Even if the validity of the Pedro scale has not been fully investigated, the reliability of this scale has been widely tested. Acceptable, good reliability ${ }^{27}$ and sufficient reliability ${ }^{24}$ was found in these studies when using the Pedro scale. However, further studies are needed to evaluate 
the validity and reliability of this tool.

\section{Data synthesis methods}

The literature review showed a variety of studies with different patient types, severity of CP, treatments (type, frequency and duration) and outcome measures. This resulted in a diverse presentation of results. In this review, the interventions were grouped and analyzed separately. The outcomes measures included trunk and posture control, balance and function. The results were analyzed in the discussion according to the presence of statistically significant differences in the studies and in every therapeutic approach and the effectiveness of the groups that presented according to outcome measures.

\section{Results}

The database research found 250 citations, of which 73 full text articles were used for evaluation (Appendix 2). Forty four articles (44) fulfilled all inclusion criteria, of which 17 were RCT's, 7 were case reports, 16 were clinical trials and 4 were pilot studies.

Search Results: 250

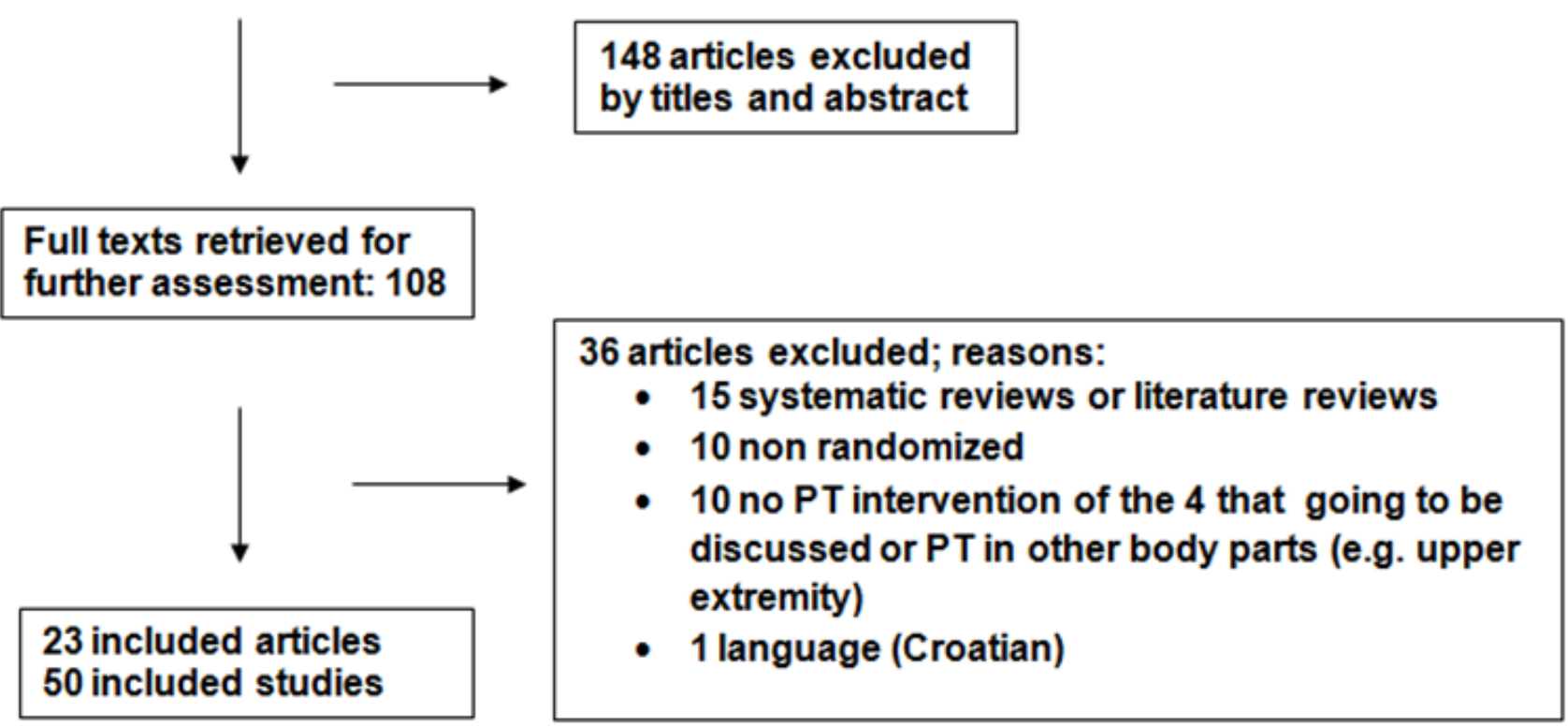

Appendix 2 Article Selection Flow

Methodological quality

The methodological quality scores of the studies are presented in Appendices 3-6. The articles that used the four therapies are mostly RCT's and clinical trials and they were evaluated by the Pedro scale. More specifically, for VR therapy there were four RCT's of which the highest was scored at $7 / 10,{ }^{28}$ the lowest at $4 / 10 .{ }^{29,30}$ and one was scores at $5 / 10 .{ }^{31}$ In hippotherapy, the highest score was $8 / 10,{ }^{32}$ another study follows with $7 / 10 .^{33}$ Moreover, two researches scored $5 / 10^{34,35}$ and the final two have $4 / 10,{ }^{36,37}$ For aquatic therapy, four RCT's analyzed scored at higher than $7 / 10,{ }^{38}$ another study at $6 / 10^{39}$ and two studies at $5 / 10 .^{40,41}$ Lastly, for the Adeli/Thera Suit therapy four RCT's, scored $7 / 10^{42}$ which was the greatest result. The lowest score was $4 / 10 .{ }^{23}$ In the middle were two studies with scores of 6/10.43,19 As mentioned above, all articles and particularly RCT's are validated by the Pedro score that they yield. The higher the score, the more acceptable and useful the article can be. It is observed that in a total of 17 articles 5 articles were of high methodological quality (scoring at 7/10 and 8/10), 8 articles were of medium methodological quality (scoring at $6 / 10$ and $5 / 10$ ). The other 4 articles were of poor methodological quality scoring at $4 / 10$.

\section{Discussion}

\section{Aquatic therapy}

Aquatic therapy is the oldest approach of the four presented. This has led to more studies of this technique. Studies that have been included report only a beneficial effect in a wide range of problems in children with CP. A lot of studies were excluded due to non compliance of the criteria. All of the studies have a plethora of outcome measures. The most common was the GMFM $(66,88)$ scale, followed by the WOTA2, PEDI, AIM, MAS and Goniometer which are observed in almost all studies. The more rare scales were the PCC, M-ABC, PSPCSA and COPM. The analysis of the studies will be mainly driven by the outcome measures.

As mentioned, an applied swimming program in children with $\mathrm{CP}$ has revealed statistically significant effect on the improvement of GMF which includes sitting and standing movements. In a pilot study differences were observed in GMFM-88 and WOTA in only one group of participants. Similar results are seen in three other studies with the same outcome measures including the MAS and the Goniometer. However, these studies are more reliable due to the 
existence and comparison of control groups. In more detail, GMF skills on land and aquatic abilities show improvement after a 6 week aquatic intervention program in $\mathrm{CP}$ children $^{41}$ and aquatic therapy can also be helpful and yield positive results in children with poor GMFCS level. ${ }^{44}$ According to Chrysagis et al., ${ }^{39}$ one thing that can be added is the possible positive effects on ROM and spasticity which are two factors that directly depend on trunk and posture.

The next study is based on a case report where after 12 weeks of aquatic therapy the results in COPM and GMFM-66 scales showed statistically significant improvement. ${ }^{45}$ Based on different scales (M-ABC \& PSPCSA) and with two groups evaluated, aquatic therapy seems to be a feasible intervention and improves GMF skills in children with CP. ${ }^{38}$ In contrast to all the other studies, only one examined the combination of aquatic and exercise therapy. The results by EMG and electrogomiometer suggest decrease on spasticity and H-reflex, two factors that disturb the posture of children with $\mathrm{CP}^{40}$ The last two studies were conducted by the same author, but examined different variables. The first study had no control group, it expressed waters'strong relationship to motor performance (sitting, standing, balance) as measured by GMFM, PEDI and AIM. ${ }^{46}$ The second study used a control group. The results were therefore more reliable. Positive effects on PEDI, AIM and PCC were reported. ${ }^{47}$

\section{Limitations \& further studies}

Despite the positive effects of aquatic therapy all studies contained several limitations such as the use of small samples and samples of convenience. This resulted in limited generalizability. The next restrictions were the time duration of the therapy and the lack of randomization and blinding. The last limitation was seen in only one article in which there was no control group. The above limitations lead to decreased validity of these articles. Finally, it was noted that two studies had no restrictions. Table 1 below shows the information of all articles in more detail. Further studies are required to evaluate this approach.

\section{Hippotherapy}

Hippotherapy is a physiotherapeutic approach widely known in the rehabilitation of children with CP. Even if its use has only begun in the last decade it was the technique with the most available studies. What was observed was that except for two studies only positive results were reported for hippotherapy. All of the studies have a diversity of outcome measures such as GMFM scales $(66,88)$. EMG, sEMG, SAS and the VMC were noted in only six studies. The following scales were observed in only five studies. These are the PBS, BPM, DLS, OLS, RFD, PEDI -FSS, five - point scale, formetic instrument system and the VGRF. The discussion of this review is based on the above scales.

Improved muscle symmetry in children with $\mathrm{CP}$, especially symmetry in adductor muscles during walking and other functional motor skills can improve during treatment with hippotherapy. ${ }^{33,34}$ This view is observed in two RCT's with the same outcome measures (EMG, sEMG and GMFM-88) and the use of groups which lead to valid results. Also, according to the $\operatorname{GMFM}(66,88)$, PEDI-FSS, DLS, OLS, VGRF and the RFD, hippotherapy indicated positive changes in trunk balance and strength and is a useful approach to maximize functional performance and reduce the degree of motor disability in children with CP. ${ }^{48-51}$ The above statement is verified in two other studies with VCM measures by the same author. In a 2009 clinical trial there was no existence of control groups and the results showed that hippotherapy improved trunk and head stability. However, in 2010 control groups were used and the results stated that hippotherapy might improve outcome measures. ${ }^{52,53}$ The second study was more reliable and valid. Nevertheless, one RCT with the occurrence of groups and the measures made by the GMFM-66 noted that CP children did not obtain clinically significant impact after hippotherapy. ${ }^{35}$

Furthermore, a trial with no control groups that used GMFM showed that hippotherapy is recommendable since it maximally mobilizes the reserve possibilities of children. ${ }^{54}$ Another trial with control groups showed that developmentally delayed children may improve GMF (Lonatamishvili et al. 2004). Another option is for hippotherapy to be used in conjunction with therapeutic exercise for the improvement of back geometry in CP. ${ }^{37}$ However, despite of the positive results of hippotherapy another study shows that hippotherapy is less effective in improving GMFM in Level V on the GMFCS. ${ }^{55}$ However, this was a case report with limited generalizability. When hippotherapy is not an accessible option, a hippotherapy simulator is a useful alternative for balance. ${ }^{36}$ Finally, the hippotherapy simulator improves posture and balance in Level V in GMFM. ${ }^{32}$

\section{Limitations \& Further studies}

The under mentioned Table 2, present the information of every article that has been analyzed and the restrictions presented below. First limitation in most of the studies was the small sample size, followed by the sample of convenience and time duration of the treatments. Two further restrictions were the lack of control groups and the diversity of subjects while there were five studies that did not mention limitations. This results in lower reliability and lack of evidence of validity. Thus, it is essential to carry out new investigations that exclude the above limitations.

\section{Virtual reality}

VR is the newest research approach of the four discussed for the treatment of CP. Even if studies are limited, especially those examining trunk and posture, VR seems like an enjoyable, safe, motivating and challenging technique. ${ }^{56}$ The following studies show that opinions vary. The results of the studies were reported using different outcome measures which will base the discussion of this report. Some of the outcome measures are GMFM-88, GMFM, TCMS, COPM, MACS, PBS, BOTMP and the posture scale analyzer. Postural scale analyzer and functional mobility was used in a case report in which there were improvements for all parameters studied such as postural control. ${ }^{57}$ Moreover, the motion of pelvis and trunk was measured by Vicon 612 optoelectronic system in another case study and indicated increase in coupling of the pelvis to the trunk, as a primary compensation mechanism utilizing the better controlled trunk to conduct rotation of the pelvis. ${ }^{58}$

However, VR is also a technique that can include games that are more affordable like Nintendo Wii or Kinect. Especially, Nintendo Wii was found to be a potential rehabilitation tool for the management of function disorders in children with CP since the GMFM- 88 showed higher scores in all sections after the treatment. ${ }^{59}$ But this was a pilot study $(n=6)$ with low generalizability. In a clinical trial, the ROM of spine and hip joints were evaluated after the implementation of serious games and noted differences between the groups were seen. This study consisted of only of two children ( $1=\mathrm{CP}, 1=$ healthy).$^{60}$ This result was confirmed by Bonnechere et al., ${ }^{61}$ who found significant differences in TCMS after treatment in the group of children with CP and suggest the integration of serious games in conventional therapy.

Furthermore, VR based therapy presented possible improvement 
in balance due to statistically significant differences found in PBS and MACS in both groups of the study (control and experimental). ${ }^{29}$ VE-based spatial training is efficient for children with a group of disabilities, specifically when combined with training that positively amends the cognitive weakness. ${ }^{62}$ That outcome came up after the second part of this trial which observed improvement in the treatment group in contrast to the first part that showed no differences occurring between groups. Training of sense of agency may help enhance the results of training programmes in children with $\mathrm{CP}$. This was noted in the experimental group when physiological habits in connection to their physical activity level and computer habits were evaluated. ${ }^{63}$ Other than these positive effects, VR also provides positive results in social engagement between non-disabled and disabled groups but no effects in motor function and there were no significant differences in COPM between groups. ${ }^{30}$ This outcome with different measures (BOTMP, GMFM, muscle strength with Cybex) was found in an RCT with only higher measurements in Cybex and the suggested 12-week hVCT protocol increases knee muscle strength than motor functions in CP children. ${ }^{31}$ Lastly, a growth in sway velocity was the only significant variation that underpinned by the force plate. The combination of anodal transcranial direct current stimulation combined with mobility training can increase the body sway velocity in children with $\mathrm{CP}$ but no relation in postural balance was noted. ${ }^{28}$

\section{Limitations \& further studies}

After the different opinions that are presented for this treatment it is reasonable to analyze the limitations of these studies. It is worth noting that for the total of eleven articles discussed, eight of them did not mention limitations, something that decrease the validity and reliability of the research and the results reported. The other three studies main limitation was the small sample sizes. The second limitation observed is the study design (pilot's studies). One study noted lack of comparison between groups and small amount of sessions (time duration). In order to alleviate the limitations further studies are needed with the exclusion of the above restrictions. Table 3 shows all of the articles details.

\section{Adeli suit-thera suit treatment}

The Adeli/Thera Suit treatment is a new physiotherapeutic technique based on re-educating the movement patterns of children with CP. This is confirmed by the following studies with some showing positive results while others oppose that view. As noted in the following table, all of the outcome measures evaluated in the studies are almost the same. The $\operatorname{GMFM}(66,88)$ scales are observed in all studies while there are two studies with the PBS and PEDI scale and only one with the EIHB. According to a case report it is highlighted that after the planned treatment of 18 weeks there was improvement in GMFM- 88 and enhanced postural balance. ${ }^{64}$ The effectiveness of the Thera Suit is also observed in a clinical trial with bigger sample size which confirms the previous study. In that trial every patient underwent a detailed evaluation and case history in order to take part in the trial. After an intensive 3-week daily program the re-examination showed a high percentage of positive effect in all patients and an overall improvement in all 5 categories of GMFM$88 . .^{65}$

Contrary to the above studies, another case report showed only a slight progress in PEDI and GMFM $(66,88)$ melioration in posture after the application of the treatment. The general opinion of this study was the attribution of minimal gains in some areas and decline in areas of functional performance. ${ }^{66}$ In a more advanced form of the above study with more samples and the establishment of control groups, the results were more unequivocal and concluded that there was no demonstrated difference between the group wearing the suit and the group wearing the control suit. ${ }^{42}$ Unlike that, there was a 3 group research (MAST group, AST group and NDT group) that after the 4 weeks treatment and at follow-up indicate the efficiency of MAST than the other two therapies in children with CP. ${ }^{19}$

A combination of different therapies was observed and used in three studies. All of the three studies showed improvement and positive effects in GMFM and PBS in CP children. More specifically, the combined therapies were the Adeli Suit and the $\mathrm{NDT}^{43}$ and the modified suit treatment along with conventional therapy ${ }^{23}$ in one case report the thera suit with intensive therapy, aquatic therapy and hippotherapy was investigated. ${ }^{67}$ This last study showed that all of the discussed therapies in this literature review can be used together in a rehabilitation program for children with $\mathrm{CP}$ and yield positive results.

\section{Limitations \& further studies}

Table 4 presents detailed information of the discussed studies. Limitations observed in the studies used were the small sample size which was the main restriction and lead to decreased variability of results. Another limitation is the time duration of the treatments which seemed in three of studies. The lack of control group was also a limitation in two studies and decreases their validity. A lack of blinding and the high cost of treatment were noted in two studies as significant limitations. Only one study had no limitations. Further studies in this treatment are necessary for creating reliable and valid results with the exclusion of the above limitations.

\section{Conclusion}

CP may be one of the most widely known pathologies in children. Hence, the problems that arise have led to new and more innovative therapies that target improved rehabilitation mainly in problems of functionality. The four techniques that have been analyzed, offer positive results in children with CP. Some of these per categories are the promotion of postural support because of the buoyancy in aquatic therapy. Moreover, the enhancement of the correct movement pattern in hippotherapy and the recovery of posture in virtual reality. Finally, the Adeli/Thera suit offers right position of the body in children with CP. However, physiotherapists should take into concern that every child with $\mathrm{CP}$ has its own clinical picture. Therefore, all of the above techniques might not fit to all children. For example, even if all of the above techniques are safe methods might pose risks depending on the severity of cases and how manageable are. Further studies are needed for the evaluation and the effectiveness of the four physiotherapeutic techniques for trunk and posture control and especially for the Adeli/ Thera Suit and Virtual Reality for children with CP. The present article is not exposed in conflict of interest, got permission to done from the Akmi Metropolitan College and is part of the dissertation of the writer job.

\section{Acknowledgements}

None.

\section{Conflict of interest}

The author declares no conflict of interest. 


\section{References}

1. Krigger K. Cerebral palsy: an overview. American Family Physician. 2006;73(91-100):101-102.

2. Abbaskhanianm A, Rashedi V, Delpak A, et al. Rehabilitation interventions for children with cerebral palsy: a systematic review. J Pediatr Rev. 2015;3(1):39-46.

3. Kruse M, Michelsen S, Flachs E, et al. Lifetime costs of cerebral palsy. Dev Med Child Neurol. 2009;51(8):622-628.

4. Alexander M, Matthews D. Pediatric Rehabilitation. 4th ed. USA: Demosmedical; 2010

5. National institute for health and care exelence. Cerebral palsy: the diagnosis and management of cerebral palsy in children and young people. UK: NICE; 2014. p. 1-14.

6. Heyrman L, Molenaers G, Desloovere K, et al. A clinical tool to measure trunk control in children with cerebral palsy: the trunk control measurement scale. Res Dev Disabil. 2011;32(6):2624-2635.

7. Saether R, Helbostad J, Adde L, et al. The relationship between trunk control in sitting and during gait in children and adolescents with cerebral palsy. Dev Med Child Neurol. 2015;57(4):344-350.

8. Harris S, Roxborough L. Efficacy and effectiveness of physical therapy in enhancing postural control in children with cerebral palsy. Neural Plast. 2005;12(2-3):229-243.

9. Pavão S, dos Santos A, de Oliveira A, et al. Functionality level and its relation to postural control during sitting-to-stand movement in children with cerebral palsy. Research in Developmental Disabilities. 2014;35(2):506-511.

10. Temcharoensuk P, Lekskulchai R, Akamanon C, et al. Effect of horseback riding versus a dynamic and static horse riding simulator on sitting ability of children with cerebral palsy: a randomized controlled trial. J Phys Ther Sci. 2015;27(1):273-277.

11. Dickinson H, Parkinson K, Ravens-Sieberer U, et al. Self-reported quality of life of 8-12-year-old children with cerebral palsy: a cross-sectional European study. Lancet. 2007;369(9580):2171-2178.

12. Orlin M, Palisano R, Chiarello L, et al. Participation in home, extracurricular, and community activities among children and young people with cerebral palsy. Developmental Medicine \& Child Neurology. 2009;52(2):160-166.

13. Anttila H, Autti-Ramo I, Suoranta J, et al. Effectiveness of physica therapy interventions for children with cerebral palsy: a systematic review. BMC Pediatrics. 2008;8(1):14.

14. Mayston M. People with cerebral palsy: effects of and perspectives for therapy. Neural Plast. 2001;8(1-2):51-69.

15. Henley C, Wollam K. Benefits and techniques of aquatic therapy. Pos t-Polio Health International. 2009. p. 57-62.

16. Bryant $\mathrm{S}$, Carter A, Cox S, et al. The HyDAT Project: UK Aquatic Physiotherapy Data Collection. London: Chartered Society of Physiotherapy; 2009. p. 7-26.

17. Kelly M, Darrah J. Aquatic exercise for children with cerebral palsy. Dev Med Child Neurol. 2005;47(12):838.

18. Zadnikar M, Kastrin A. Effects of hippotherapy and therapeutic horseback riding on postural control or balance in children with cerebral palsy: a meta-analysis. Developmental Medicine \& Child Neurology. 2011;53(8):684-691.

19. Khayatzadeh Mahani M, Karimloo M, Amirsalari S. Effects of Modified Adeli Suit Therapy on Improvement of Gross Motor Function in Children With Cerebral Palsy. Hong Kong Journal of Occupational Therapy. 2011;21(1):9-14
20. Sveistrup H. Motor rehabilitation using virtual reality. J Neuroeng Rehabil. 2004;1(1):10.

21. Bonnechère $\mathrm{B}$, Omelina $\mathrm{L}$, Jansen $\mathrm{B}$, et al. Balance improvement after physical therapy training using specially developed serious games for cerebral palsy children: preliminary results. Disabil Rehabil. 2015;39(4):403-406.

22. Turner AE. The efficacy of Adeli suit treatment in children with cerebral palsy. Dev Med Child Neurol. 2006;48(5):324.

23. Alagesan J, Shetty A. Effect of modified suit therapy in spastic diplegic cerebral palsy - a single blinded randomized controlled trial. Journal of Health and Allied Sciences. 2010;9(4):14.

24. Maher C, Sherrington C, Hebert R, et al. Reliability of the PEDro scale for rating quality of randomized controlled trials. Phys Ther. 2003;83(8):713-721

25. Foley N, Bhogal S, Teasell R, et al. Estimates of quality and reliability with the physiotherapy evidence-based database scale to assess the methodology of randomized controlled trials of pharmacological and nonpharmacological interventions. Phys Ther. 2006;86(6):817-824.

26. de Morton N. The PEDro scale is a valid measure of the methodological quality of clinical trials: a demographic study. Aust J Physiother. 2009;55(2):129-133.

27. Macedo L, Elkins M, Maher C, et al. There was evidence of convergent and construct validity of Physiotherapy Evidence Database quality scale for physiotherapy trials. J Clin Epidemiol. 2010;63(8):920-925.

28. Lazzari R, Politti F, Santos C, et al. Effect of a single session of transcranial direct-current stimulation combined with virtual reality training on the balance of children with cerebral palsy: a randomized, controlled, double-blind trial. J Phys Ther Sci. 2016;27(3):763-768.

29. Deepak S, Ajeesh PS, Rameshkumar R, et al. Virtual reality based therapy for post operative rehabilitation of children with cerebral palsy. Work (Reading, Mass.). 2012;41(1):3612-3615.

30. Reid D, and Campbell K. The Use of virtual reality with children with cerebral palsy: a pilot randomized trial. Therapeutic Recreation Journal. 2016;40(4):255-268.

31. Chen C, Hong W, Cheng H, et al. Muscle strength enhancement following home-based virtual cycling training in ambulatory children with cerebral palsy. Res Dev Disabil. 2012;33(4):1087-1094.

32. Herrero P, Gomez-Trullen E, Asensio A, et al. Study of the therapeutic effects of a hippotherapy simulator in children with cerebral palsy: a stratified single-blind randomized controlled trial. Clin Rehabil. 2012;26(12):1105-1113.

33. McGibbon N, Benda W, Duncan B, et al. Immediate and long-term effects of hippotherapy on symmetry of adductor muscle activity and functional ability in children with spastic cerebral palsy. Archives of Physical Medicine and Rehabilitation. 2009;90(6):966-974.

34. Benda W, Mc Gibbon N, Grant K. Improvements in Muscle Symmetry in Children with Cerebral Palsy After Equine-Assisted Therapy (Hippotherapy). J Altern Complement Med. 2003;9(6):817-825.

35. Davis E, Davies B, Wolfe R, et al. A randomized controlled trial of the impact of therapeutic horse riding on the quality of life, health, and function of children with cerebral palsy. Dev Med Child Neurol. 2009;51(2):111-119.

36. Lee $\mathrm{C}, \mathrm{Kim} \mathrm{S}, \mathrm{Na} \mathrm{S}$. The Effects of hippotherapy and a horse riding simulator on the balance of children with cerebral palsy. J Phys Ther Sci. 2014;26(3):423-425.

37. El-Meniawy G, Thabet N. Modulation of back geometry in children with spastic diplegic cerebral palsy via hippotherapy training. Egyptian Journal of Medical Human Genetics. 2012;13(1):63-71.

38. Hillier S, McIntyre A, Plummer L. Aquatic physical therapy for children with developmental coordination disorder: a pilot randomized controlled trial. Phys Occup Ther Pediatr. 2010;30(2):111-124. 
39. Chrysagis N, Douka A, Nikolopoulos M, et al. Effects of an aquatic program on gross motor functionof children with spastic cerebral palsy. Journal Biology of Exercise. 2009. 5 p.

40. Olama K, Kaseem H, Abolazm S. Impact of aquatic exercise program on muscle tone in spastic hemiplegic children with cerebral palsy. Clinical Medicine Journal. 2015;1(4):138-144.

41. Dimitrijević L, Aleksandrović M, Madić D, et al. The effect of aquatic intervention on the gross motor function and aquatic skills in children with cerebral palsy. Journal of Human Kinetics. 2012;32(-1):167-174

42. Bailes A, Greve K, Burch C, et al. The effect of suit wear during an intensive therapy program in children with cerebral palsy. Pediatr Phys Ther. 2011;23(2):136-142.

43. Kim M, Lee B, Park D. Effects of combined Adeli suit and neurodevelopmental treatment in children with spastic cerebral palsy with gross motor function classification system levels I and II. Hong Kong Physiotherapy Journal. 2016;34:10-18.

44. Lai C, Liu W, Yang T, et al. Pediatric aquatic therapy on motor function and enjoyment in children diagnosed with cerebral palsy of various motor severities. J Child Neurol. 2014;30(2):200-208.

45. Retarekar R, Fragala-Pinkham M, Townsend E. Effects of aquatic aerobic exercise for a child with cerebral palsy: single-subject design. $P e-$ diatric Physical Therapy. 2009;21(4):336-344.

46. Getz M, Hutzler Y, Vermeer A. The relationship between aquatic independence and gross motor function in children with neuro-motor impairments. European Journal of Special Needs Education, 2006;23(4):339-355

47. Getz M, Hutzler Y, Vermeer A. The effects of aquatic intervention on perceived physical competence and social acceptance in children with cerebral palsy. European Journal of Special Needs Education. 2007;22(2):217-228

48. Drnach M, O'Brien P, Kreger A. The effects of a 5-week therapeutic horseback riding program on gross motor function in a child with cerebral palsy: a case study. The Journal of Alternative and Complementary Medicine. 2010;16(9):1003-1006.

49. Giagazoglou P, Arabatzi F, Dipla K, et al. Effect of a hippotherapy intervention program on static balance and strength in adolescents with intellectual disabilities. Res Dev Disabil. 2012;33(6):2265-2270.

50. Park E, Rha D, Shin J, et al. Effects of hippotherapy on gross motor function and functional performance of children with cerebral palsy. Yonsei Medical Journal. 2014;55(6):1736.

51. Sterba J, Rogers B, France A, et al. Horseback riding in children with cerebral palsy: effect on gross motor function. Dev Med Child Neurol. 2002;44(05):301-308

52. Shurtleff T, Standeven J, Engsberg J. Changes in dynamic trunk/head stability and functional reach after hippotherapy. Arch Phys Med Rehabil. 2009;90(7):1185-1195.

53. Shurtleff T, Engsberg J. Changes in trunk and head stability in children with cerebral palsy after hippotherapy: a pilot study. Phys Occup Ther Pediatr. 2010;30(2):150-163

54. Winchester P, Kendall K, Peters H, et al. The effect of therapeutic horseback riding on gross motor function and gait speed in children who are developmentally delayed. Physical \& Occupational Therapy In Pediatrics. 2002;22(3):37-50.

55. Hamill D. Washington K, White O. The effect of hippotherapy on postural control in sitting for children with cerebral palsy. Phys Occup Ther Pediatr. 2007;27(4):23-42.

56. Weiss P, Tirosh E, Fehlings D. Role of virtual reality for cerebral palsy management. Journal of Child Neurology. 2014;29(8):1119-1124.
57. Deutsch J, Borbely M, Filler J, et al. Use of a low-cost, commercially available gaming console (Wii) for rehabilitation of an adolescent with cerebral palsy. Phys Ther. 2008;88(10):1196-1207.

58. Barton G, Hawken M, Foster R, et al. The effects of virtual reality game training on trunk to pelvis coupling in a child with cerebral palsy. J Neuroeng Rehabil. 2013;10(1):15.

59. Gordon C, Roopchand-Martin S, Gregg A. Potential of the Nintendo Wii $^{\mathrm{TM}}$ as a rehabilitation tool for children with cerebral palsy in a developing country: a pilot study. Physiotherapy. 2012;98(3):238-242.

60. Barton G, Holmes G, Hawken M, et al. A virtual reality tool for training and testing core stability: A pilot study. Gait \& Posture, 2006;24(2):S101-102.

61. Bonnechère $\mathrm{B}$, Omelina $\mathrm{L}$, Jansen $\mathrm{B}$, et al. Balance improvement after physical therapy training using specially developed serious games for cerebral palsy children: preliminary results. Disabil Rehabil. 2015;39(4):403-406.

62. Akhutina T, Foreman N, Krichevets A, et al. Improving spatial functioning in children with cerebral palsy using computerized and traditional game tasks. Disabil Rehabil. 2003;25(24):1361-1371.

63. Ritterband-Rosenbaum A, Christensen M, Nielsen J. Twenty weeks of computer-training improves sense of agency in children with spastic cerebral palsy. Research in Developmental Disabilities. 2012;33(4):1227-1234.

64. Ko M, Lee J, Kang S, et al. Effect of Adeli suit treatment on gait in a child with cerebral palsy: a single-subject report. Physiotherapy Theory and Practice. 2014;31(4):275-282.

65. Kunz A, Golaszewski S, Hardy J, et al. The treatment of cerebral palsy with a special neurorehabilitation programme Report of 100 patients analysed with the Gross Motor Function Measure. Austria; 20006. p. $1-16$.

66. Bailes A, Greve K, Schmitt L. Changes in two children with cerebral palsy after intensive suit therapy: a case report. Pediatr Phys Ther. 2010;22(1):76-85.

67. Datorre E. Intensive therapy combined with strengthening exercises using the thera suit in a child with CP: A case report. 2013. p. 1-25.

68. Jorgic B, Dimitrijevic L, Aleksandrovic M, et al. The swimming program effects on the gross motor function, mental adjustment to the aquatic environment, and swimming skills in children with cerebral palsy: A pilot study. Specijalna edukacijai rehabilitacija, 2012;11(1):51-66.

69. Ionatamishvili $\mathrm{N}$, Tsverava D, Loriya $\mathrm{M}$, et al. Riding therapy as a method of rehabilitation of children with cerebral palsy. Human Physiology. 2004;30(5):561-565.

70. Park E, Rha D, Shin J, et al. Effects of hippotherapy on gross motor function and functional performance of children with cerebral palsy. Yonsei Medical Journal. 2014;55(6):1736.

71. Bar-Haim S, Harries N, Belokopytov M, et al. Comparison of efficacy of Adeli suit and neurodevelopmental treatments in children with cerebral palsy. Dev Med Child Neurol. 2006;48(05):325-330.

72. Sanger T, Delgado M, Gaebler-Spira D, et al. Classification and definition of disorders causing hypertonia in childhood. Pediatrics. 2003;111(1):e89-e97.

73. Delgado M, Albright A. Movement disorders in children: definitions, classifications, and grading systems. J Child Neurol. 2003;18(1):s1-8.

74. Jeon J, Shin W. Reliability and validity of the Korean version of the trunk control measurement scale (TCMS-K) for children with cerebral palsy. Res Dev Disabil.. 2014;35(3):581-590. 
Appendix 3 Comparison of PEDRO scores in Aquatic Therapy

\begin{tabular}{|c|c|c|c|c|}
\hline & Chrysagis et al. ${ }^{39}$ & Olama et al. ${ }^{40}$ & Hiller et al. ${ }^{38}$ & Dimitrijevic et al. ${ }^{41}$ \\
\hline I. Random & Yes & Yes & Yes & Yes \\
\hline 2. Concealed Allocation & Yes & No & Yes & No \\
\hline 3. Baseline Comparability & Yes & Yes & Yes & Yes \\
\hline 4. Blind Subjects & No & No & No & No \\
\hline 5. Blind Therapists & No & No & No & No \\
\hline 6. Blind Assessors & No & No & Yes & No \\
\hline 7. Adequate Follow-up & Yes & Yes & Yes & Yes \\
\hline 8. Intention-to-Treat & No & No & No & No \\
\hline 9. Between Group & Yes & Yes & Yes & Yes \\
\hline I0. Point Estimates \& Variability & Yes & Yes & Yes & Yes \\
\hline Total Score & I0-Jun & I0-May & I0-Jul & I0-May \\
\hline
\end{tabular}

Appendix 4 Comparison of PEDRO scores in Hippotherapy

\begin{tabular}{|c|c|c|c|c|c|c|}
\hline & $\begin{array}{l}\text { Lee et } \\
\text { al. } .^{36}\end{array}$ & $\begin{array}{l}\text { Benda et } \\
\text { al. }{ }^{34}\end{array}$ & $\begin{array}{l}\text { El-Meniawy \& } \\
\text { Thabet }^{37}\end{array}$ & $\begin{array}{l}\text { Davis et } \\
\text { al. } .^{35}\end{array}$ & $\begin{array}{l}\text { Herrero et } \\
\text { al. }\end{array}$ & $\begin{array}{l}\text { McGibbon et } \\
\text { al. }^{33}\end{array}$ \\
\hline I. Random & Yes & Yes & Yes & Yes & Yes & Yes \\
\hline $\begin{array}{l}\text { 2. Concealed } \\
\text { Allocation }\end{array}$ & No & Yes & No & Yes & Yes & Yes \\
\hline $\begin{array}{l}\text { 3. Baseline } \\
\text { Comparability }\end{array}$ & Yes & No & Yes & Yes & Yes & Yes \\
\hline 4. Blind Subjects & No & No & No & No & No & No \\
\hline 5. Blind Therapists & No & No & No & No & No & No \\
\hline 6. Blind Assessors & No & No & No & No & Yes & Yes \\
\hline 7. Adequate Follow-up & No & Yes & No & No & Yes & Yes \\
\hline 8. Intention-to-Treat & No & No & No & No & Yes & No \\
\hline 9. Between Group & Yes & Yes & Yes & Yes & Yes & Yes \\
\hline $\begin{array}{l}\text { 10. Point Estimates \& } \\
\text { Variability }\end{array}$ & Yes & Yes & Yes & Yes & Yes & Yes \\
\hline Total Score & 10-Apr & 10-May & 10-Apr & 10-May & 10-Aug & I0-Jul \\
\hline
\end{tabular}

Appendix 5 Comparison of PEDRO scores in Virtual Reality

\begin{tabular}{lllll}
\hline & Lazzari et al. ${ }^{28}$ & Deepak et al. ${ }^{29}$ & Reid \& Campbell $^{\mathbf{3 0}}$ & Chen et al. $^{{ }^{31}}$ \\
\hline I. Random & Yes & Yes & Yes & Yes \\
2. Concealed Allocation & No & No & No & No \\
3. Baseline Comparability & Yes & Yes & No & Yes \\
4. Blind Subjects & Yes & No & No & No \\
5. Blind Therapists & Yes & No & No & No \\
6. Blind Assessors & No & No & Yes & No \\
7. Adequate Follow-up & Yes & No & No & Yes \\
8. Intention-to-Treat & No & No & No & No \\
9. Between Group & Yes & Yes & Yes & Yes \\
10. Point Estimates \&Variability & Yes & Yes & Yes & Yes \\
Total Score & I0-Jul & I0-Apr & 10-Apr & 10-May \\
\hline
\end{tabular}


Appendix 6 Comparison of PEDRO scores in Adeli Suit - Thera Suit

\begin{tabular}{lllll}
\hline & Alagesan \& Shetty ${ }^{23}$ & Kim et al. ${ }^{43}$ & Bailes et al. ${ }^{42}$ & Mahani et al. 20II \\
\hline I. Random & Yes & Yes & Yes & Yes \\
2. Concealed Allocation & No & No & No & No \\
3. Baseline Comparability & No & Yes & Yes & Yes \\
4. Blind Subjects & No & No & No & No \\
5. Blind Therapists & No & No & No & No \\
6. Blind Assessors & Yes & Yes & Yes & Yes \\
7. Adequate Follow-up & No & Yes & Yes & Yes \\
8. Intention-to-Treat & No & No & Yes & No \\
9. Between Group & Yes & Yes & Yes & Yes \\
10. Point Estimates \&Variability & Yes & Yes & Yes & Yes \\
Total Score & I0-Apr & 10-Jun & I0-Jul & 10-Jun \\
\hline
\end{tabular}

